\title{
Meta
}

Journal des traducteurs

Translators' Journal

\section{Sticky Captions: Genre-internal Variation in Print-based Ad Translating}

\section{Maria Sidiropoulou}

Volume 53, numéro 3, septembre 2008

URI : https://id.erudit.org/iderudit/019235ar

DOI : https://doi.org/10.7202/019235ar

Aller au sommaire du numéro

\section{Éditeur(s)}

Les Presses de l'Université de Montréal

ISSN

0026-0452 (imprimé)

1492-1421 (numérique)

Découvrir la revue

Citer cet article

Sidiropoulou, M. (2008). Sticky Captions: Genre-internal Variation in Print-based Ad Translating. Meta, 53(3), 471-489.

https://doi.org/10.7202/019235ar

\section{Résumé de l'article}

Cette étude montre que les versions sources et cibles des annonces peuvent refléter avec justesse les préférences linguistiques des environnements sources et cibles. Elle fait ressortir les préférences linguistiques du discours propres à chaque culture, genre et sexe. Elle examine la variation interne du genre dans un paradigme de traduction anglais-grec, et elle explore la variation dans les préférences discursives des versions cibles des annonces de cosmétiques. Si les versions sources et cibles des annonces reflètent une hiérarchie sociale, on peut tirer de nombreuses conclusions sur le pouvoir de la publicité pour détecter de fines distinctions selon l'identité culturelle. 


\title{
Sticky Captions: Genre-internal Variation in Print-based Ad Translating
}

\author{
MARIA SIDIROPOULOU \\ National and Kapodistrian University of Athens, Athens, Greece \\ msidirop@enl.uoa.gr
}

\begin{abstract}
RÉSUMÉ
Cette étude montre que les versions sources et cibles des annonces peuvent refléter avec justesse les préférences linguistiques des environnements sources et cibles. Elle fait ressortir les préférences linguistiques du discours propres à chaque culture, genre et sexe. Elle examine la variation interne du genre dans un paradigme de traduction anglaisgrec, et elle explore la variation dans les préférences discursives des versions cibles des annonces de cosmétiques. Si les versions sources et cibles des annonces reflètent une hiérarchie sociale, on peut tirer de nombreuses conclusions sur le pouvoir de la publicité pour détecter de fines distinctions selon l'identité culturelle.
\end{abstract}

\section{ABSTRACT}

The study shows that source and target versions of ads can accurately mirror linguistic preference across source and target environments. It points to culture-specific, genrespecific and gender-specific linguistic preference imprinted in ad discourses. It examines genre-internal variation in print-based advertising in the English-Greek translation paradigm. It explores variation in discursive preference manifested in target versions of business-oriented and cosmetics ads, with a view to indicating that male and female audiences are attributed different social needs in the target environment. If ST/TTs of ads reflect culture-specific hierarchies of deeply felt needs in a society, a lot can be concluded about the immense power of advertising to register fine distinctions with respect to cultural versions of identities, to mould cultural audiences' expectations and to create new social values in target environments.

\section{MOTS-CLÉS/KEYWORDS}

advertisement translation, English-Greek translation, identity inscription, culture/genre/ gender-related variation

"Ads, the most public of discourses, adopt the strategies of the most private" (Cook 1992: 180)

\section{Ad Translating: Topics and Issues}

Advertising has attracted researchers' attention from various disciplines such as anthropology, sociology, linguistics, media research. In linguistics, attention has been drawn to pragmatic/cognitive, semiotic and cultural issues that relate to processing the visual, verbal and acoustic aspects of messages, as well as the ideological dimension underlying meaning transfer.

Advertising in translation offers researchers a unique opportunity to examine how aspects of messages may be treated across languages. Visual/verbal/acoustic text in ads is short and rich in meaning, while the need of ad producers to appeal to consumers is urgent. This is probably why linguistic and cultural preference in the 
construction of source/target versions of messages is imprinted with precision for the intended effect to be achieved. The need of manufacturers to create advertising appeal and the fact that advertising styles "have kept pace with changes in social awareness" (Adab and Valdés 2004: 163) make advertising messages an invaluable resource for theoretical observations. Advertising employs visual and aural stimuli to help consumers recover covertly communicated assumptions (Cook 1992; Myers 1994; Tanaka 1994; Goddard 1998). In ad translating, visual messages and sound effects are usually transferred intact across languages. Attention is, thus, directed in this paper to the ways in which verbal messages may be reshuffled across languages to cater for the linguistic and cultural profile of target audiences and markets.

The data in the present study is typical of what might appear in high circulation Greek newspapers/magazines and on Greek TV. It consists of three sets of EnglishGreek ad pairs that cover a fairly wide range of ad types in terms of commodity advertised and medium of transmission. It comprises (1) a set of ads promoting business-oriented commodity types, (2) a set of cosmetics ads, which make appeal to sensual pleasure, and (3) a set of TV spots ${ }^{1}$ which advertises commodity types that relate to everyday activity and leisure. Ads are randomly selected and are intended to test the hypotheses that

(a) types of variation which systematically appear in other genres, in English-Greek translation (Sidiropoulou 2004), also appear between ST/TT versions of English-Greek ad discourses. TV spots are employed to verify culturally preferred linguistic tendencies, in oral speech, as in print-based advertising. A second hypothesis is that

(b) there is variation in the treatment of textual features between target versions of business-oriented and cosmetics ad types. It is shown that the gender of intended addressees influences the treatment of target linguistic features in various ways.

The study examines genre-internal variation in the translation of print-based advertising between English and Greek. Target versions of advertisements from Greek newspapers and magazines are contrasted with their English source versions to reveal variation in inscription of identities across cultures. Identities are reflected through linguistic preference registered in different categories of ads and variation in translator behaviour relative to pragmatic/cognitive variables. Source and target versions of ads "mirror" varied consumer profiles through culturally preferred patterns of linguistic behaviour.

The ultimate purpose of the advertiser is to change the thinking of both interested and uninterested people. The persuasive force of ad discourse must occur through culturally preferred patterns of linguistic behaviour. In ad translation, this is attempted through translators' sub/consciously erasing signs of foreignness from discourses to inscribe domestic preferences that facilitate processing and persuasion. The translation strategies in the present data set fall within the three last categories of strategies anticipated in Smith and Klein-Braley (1995). Smith and Klein-Braley have shown translator-trainees how far professionals can go into shifting features, between German and English, in ad translation, in order to produce a culturally effective text. They have distinguished the following strategies in terms of the liberty translators and advertisers have taken in treating text and visuals. 
SMITH AND KLEIN-BRALEY (1995: 182-183) - AD TRANSLATION STRATEGY SCHEME (adapted)

1. Don't Change Advertisements: retain both graphics and text

2. Export Advertisements

3. Straight Translation Advertisements

4. Adaptation Advertisements: keep visuals, change text slightly or significantly

5. Revision Advertisements: keep visuals, write new text

6. Different Advertisements: different visuals and texts for each country.

\section{Advertising Data: A Microcosm}

Advertisement translators face almost all kinds of problems: prosodic, pragmatic, syntactic, textual, semiotic or other. In fact, such short but complex and culturally complete texts can provide "valuable insights into possible strategies and methods" for dealing with phenomena in other longer texts, whether literary or non-literary (Smith and Klein-Braley 1995:173). Advertising data is itself a microcosm in which intercultural difference in tendencies and constraints is most accurately reflected and can allow safe conclusions about cultural identities. Juxtaposition of source and target versions of ads raises awareness of cultural preference, because it highlights tendencies in domestic message construction that would have gone unnoticed otherwise.

Variation across languages in advertising may be attributed to a number of factors. These may range from

(a) intercultural difference in the persuasion strategies preferred across cultures, to

(b) variation in the generic constraints operating across a particular language pair, and from

(c) the profile of potential consumers (Fowles 1996) to

(d) the type of commodity advertised. "Soft-sell" approaches to advertising (for perfumes, cosmetics, beers, liquor) differ from "hard-sell" ones (for office equipment, Rotzoll 1985).

Examples in the following sections show instances of intercultural variation inscribed in English-Greek ad pairs which relate to factors (a) and (b) above. This is to show that, for factors (a) and (b), print-based ads can inscribe cultural preference with precision and can, therefore, be invaluable tools in exploring identities through translation. In section 3 , the focus is on factors (c) and (d) and examples are intended to reveal more of the complexities involved in the transfer of advertising messages.

\subsection{Persuasion in Ads}

Persuasion strategies are culture specific. In discourse types such as advertisements, in which persuasion is a primary goal, persuasive strategies are manipulated in translation to meet target audience expectations. An instance of intercultural difference manifestation between English and Greek, in the context of ad translation (and elsewhere), is a preference for signaling logical relations between propositions in Greek. In Greek, the responsibility for signaling discourse relations seems to fall to the speaker rather than the addressee (Sidiropoulou 2004) and thus in $\mathrm{E} \rightarrow \mathrm{G}$ translation, translators usually add connectives to improve TT texture. This tendency for 
making discourse connectives explicit in a TT may be assumed to be a mere manifestation of the explicitation tendency in translation. In the English-Greek paradigm, however, it seems to be more than that. The preference for signaling discourse connection, in the present data set, has been assumed to be a combination of two parallel forces. On the one hand, it is a manifestation of the translator's tendency to make things explicit for target readers and, on the other, it is a manifestation of the cultural preference that considers signaling logical relations, in Greek, a responsibility of text producer rather than addressee. In TT1, a because ( $y \iota \alpha \tau i$ ) connective shows this tendency for signaling discourse relations in target persuasion strategy. ST "[]" indicates absence of a linguistic sign and, thus, a point of contrast between source and target versions.

ST1 JUVENA - TIME STOP GEL. Your Skin Feels Reborn

[] TIME STOP GEL by JUVENA can activate the skin's natural regeneration process more than ever before. This revolutionary treatment makes your skin continuously smoother and softer. Its secret is the advanced technology of AHA plus - the first Alpha Hydroxy System of the second generation:...

JUVENA OF SWITZERLAND. THE ESSENCE OF BEAUTY. (Marie Claire, March 1995)

TT1 JUVENA - TIME STOP GEL. ...And your Skin Feels as if reborn!

Because within TIME STOP GEL the power of the AHA plus system is hidden. This system contains the skin-friendly Alpha-Hydroxy-Acid and Map... JUVENA OF SWITZERLAND. THE KNOWLEDGE OF BEAUTY.

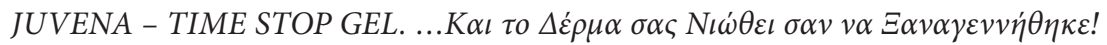

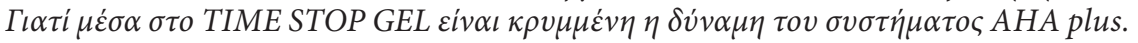

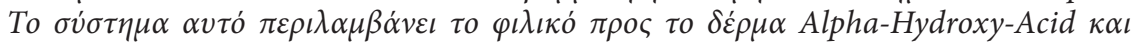
MAP...

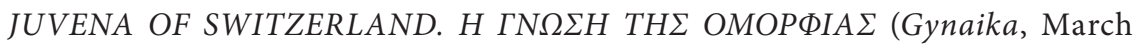
1995).

Ex. 1 additionally presents variation in discursive preference other than the one mentioned above, which is in favour of the claim that ads can accurately mirror linguistic preference across cultures. E.g., ST time expression more than ever before is avoided in TT, evidently because it does not fit the preference of Greek for future orientation in time reference. ST more than ever before has an orientation towards the past. This is variation manifested in the orientation of temporal expressions in English $\rightarrow$ Greek news reporting translation, which has been attributed to a culture specific linguistic preference in time specification (Sidiropoulou 2004).

Preference for signaling discourse connection explicitly in Greek is also reflected in oral messages, in the Greek $\rightarrow$ English advertising business. In the Greek $\rightarrow$ English translation direction, explicit discourse connectives are expected to disappear or be made implicit in the English target version of ads. ST2 presents a fragment of the verbal stimuli that accompanies a TV spot advertising a Finnish dairy manufacturer, VALIO, on Greek TV. The English TT below has appeared in subtitles, the Greek ST is voiced-over. A connective of purpose in Greek $(\gamma \iota \alpha v \alpha)$ is made implicit in terms of English TT connective and in the subtitles. Cook (1992: 154) notes that conjunctions are "notoriously absurd in ads and an easy target for analysts obsessed with demonstrating ads' 'illogicality."' In Greek, persuasion seems to require clarity of conjunction and, thus, the source preference for "illogicality" is abandoned. 
ST2 (voice-over)

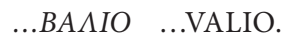

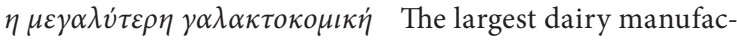
$\varepsilon \tau \alpha \iota \rho \varepsilon i \alpha \sigma \tau \eta \Phi \iota \lambda \alpha v \delta i \alpha$ turer in Finland offers

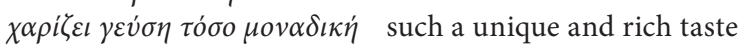

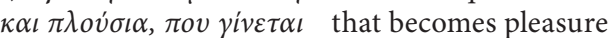
$\alpha \pi \delta ́ \lambda \alpha v \sigma \eta$ to bring

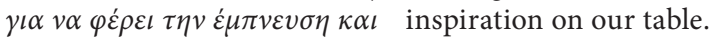
$\sigma \tau o \tau \rho \alpha \pi \dot{\varepsilon} \zeta \iota \mu \alpha \varsigma$.

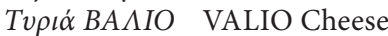

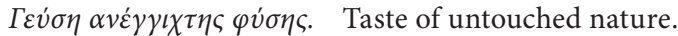

TT2 (subtitles)

...VALIO,

The largest dairy manufacturer in Finland offers such a unique and rich taste that becomes pleasure and brings inspiration on our table.

VALIO

Taste of untouched nature.

Similarly, in exs. 3 and 4, contrasts are downgraded in English TT. ST3 advertises AMITA MOTION juice, on Greek TV, an official sponsor for the then-upcoming Olympic Games, Athens 2004. TT3 appears in subtitles (not shown on Greek TV) to guide foreign companies through the verbal, visual and aural stimuli. A Greek ST connector but also $(\alpha \lambda \lambda \dot{\alpha} \kappa \alpha \iota)$, in the following ad, is made implicit in terms of TT item and.

ST3 (heard)

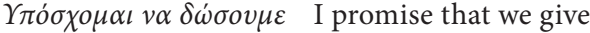

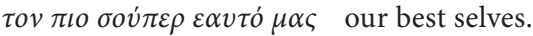

'O

$\alpha \lambda \lambda \alpha \dot{\alpha} \kappa \alpha \iota$ o $\alpha \alpha \theta \dot{v} v \alpha \varsigma$ but also each one of us $\xi \varepsilon \chi \omega \rho \iota \sigma \tau \dot{\alpha}$. separately.

$\Gamma\llcorner\alpha v \alpha \mu \varepsilon \tau \alpha \delta \omega \sigma \sigma o v \mu \varepsilon$ To transfer positive energy $\theta \varepsilon \tau \iota \kappa \eta ் ~ \varepsilon v \varepsilon ́ \rho \gamma \varepsilon ı \alpha \quad$ to the whole of Greeeeeece!... $\sigma \varepsilon \dot{\alpha} \lambda \eta \tau \eta v E \lambda \lambda \dot{\alpha} \delta \alpha \alpha \alpha \alpha \alpha \alpha$ !..
TT3 (subtitles)

I promise that we will give... our best selves. Altogether and each one of us separately...

To fill every corner of Greece with positive energy...

\section{AMITA MOTION}

Official Sponsor of Positive Energy for the Olympic Games, Athens 2004.

Contrasts are not solely expressed between propositions as in ex. 3, they may even be implied or stated between noun phrases. In ex. 4, a fragment from a COSMOTE telecommunications TV spot, the contrast between Greek ST items whole (ó $\lambda \eta$ ) and one $(\mu \iota \alpha)$ is de-emphasized in English TT. The whole intensifier, in the Greek ST item the whole of Greece, is omitted from the English TT, while copula verb recovery (is, last line TT4), downgrades the contrast even further.

ST4 (heard)

$\Sigma \tau \varepsilon i \lambda \tau \varepsilon \tau \alpha \pi \iota \dot{\zeta} \zeta v \tau \tau \alpha v \dot{\alpha} \quad$ Send the most vivid $\mu \eta v \dot{\mu} \mu \alpha \tau \alpha$.

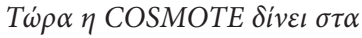

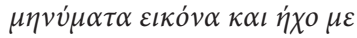

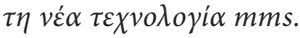

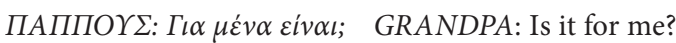
EГTONOL: GRANDSON:

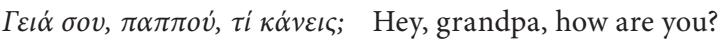

TT4 (subtitles)

Send now the most vivid messages

COSMOTE now offers image and sound to instant messaging thanks to the new mms service.<smiles>[Mg]</smiles>

GRANDPA: Is it for me? GRANDSON:

Hey, grandpa, how are you? 
'O $\lambda \eta \eta E \lambda \lambda \dot{\alpha} \delta \alpha$ The whole of Greece,

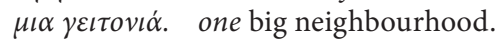

'O $\eta \eta \eta E \lambda \lambda \dot{\alpha} \delta \alpha$ The whole of Greece,

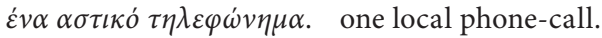

[] Greece is one big neighbourhood.

[] Greece is one local phone-call.

Making discourse connection implicit in target versions of Greek $\rightarrow$ English translation situations suggests that the preference for strengthening discourse connection in the English $\rightarrow$ Greek translation direction is not solely a manifestation of explicitation tendency, but also a culturally preferred pattern in Greek persuasion strategy. The above examples show that ad translation can accurately reflect variation in the persuasion strategies preferred across cultures. Enforcing discourse connection runs through most ad types in the present data and, hence, it is a fairly strong preference in Greek ads. It may be assumed to be a manifestation of a positive politeness intention in interaction: speakers tend to contribute more input to facilitate interaction.

Exceptions to the rule do appear occasionally and are assumed to be due to complexities in the transfer of ad messages. For instance, this enforcing-the-discourse-connection tendency is occasionally abandoned (as in the MAX FACTOR Get-even advertisement, ex. 14, below) in Greek, and the shift is attributed to a need for interpersonal distance between advertiser and consumer to be adjusted to culturally preferred patterns of linguistic behaviour.

\subsection{Generic Constraints in Ad Discourses}

An instance of variation factor (b), referred to above, namely, variation in generic constraints operating across a particular language pair, appears in ex. 5. It is presented here to show that ads reflect generically preferred discursive tendencies with precision. Source and target versions use similar visuals, layout and font size, but the text is somewhat different in content, to reveal a difference in generic conventions prevalent across English-Greek.

ST5 The endless waters of the Pacific Ocean glitter below you.

Even though you are not flying with us, each mile counts.

In Lufthansa Miles \& More.

In our Miles \& More frequent flyer program, you can collect mileage credits even when you fly with our partners, United Airlines and Thai Airways International. Taken together, the three airlines have the world's largest combined network of destinations. And for every flight you take in that network, each mile counts toward your Lufthansa bonus. (Time, March 13, 1995)

TT5 If you overslept in the morning, if you didn't get a taxi in time, at noon, and missed your flight, now you have a third opportunity to fly to Frankfurt directly.

So, don't you worry.

Because from March 26, Lufthansa flies you to Frankfurt directly, ... And, of course, you have one more opportunity to fly to Frankfurt... but also to benefit from the frequent flyer programme Miles and More of Lufthansa. Isn't it surprising how far Lufthansa can take you?

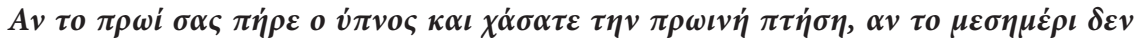

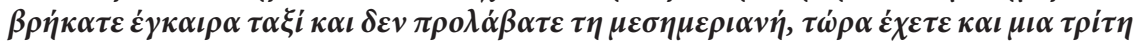

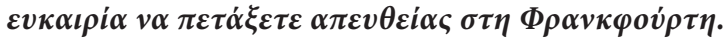

Г'’ $\alpha \tau o ́, \mu \eta v \alpha v \eta \sigma v \chi \varepsilon i \tau \varepsilon$. 


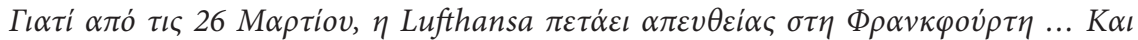

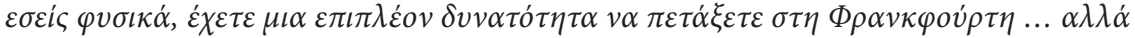

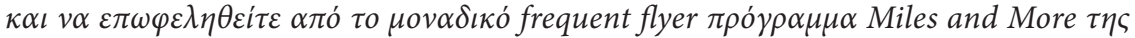

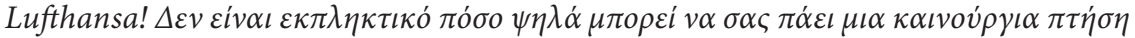

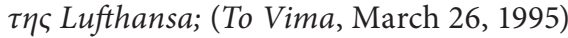

Observation of press news headlines, in translation, has shown that Greek target press headlines differ from their English source versions with respect to the quality and quantity of information they convey, thus, revealing a difference in generic constraints operating in the two environments. Greek target news headlines have been more informative than their English source counterparts, while English headlines have been more allusive and emotive (Sidiropoulou 1995). Ex. 5 is a fragment of a Lufthansa advertisement which appeared in a high circulation Greek newspaper. The Greek TT conforms to some generic constraint which crosses out allusive material of artistic quality from the ad headline to allow more descriptive and non-emotive information. ${ }^{3}$

The examples referred to in this study come from commercial advertising. Ex. 6 stands out in that it comes from public benefit advertising: it is an awareness-raising ad pair which intends to make refugee reception smoother in host societies. As Séguinot (1994: 263) claims, in promotional material "the success of a translation is a function of the relationships the text has with its context, the visuals accompanying it and the preparation of the market." In ex. 6, the visuals that accompany the ST and TT vary marginally, while the source and target texts promote a different image of refugees: in ST the refugee is identified in terms of whether the person carries his tools or not (1. 1-2). TT promotes a more "realistic" image, in that it allows the presupposition that the refugee may be assumed to be the shabby one. No matter the variation in both text and visuals (this is category 6 of the Smith and Klein-Braley strategy scheme), the Greek TT headline conforms to the generic constraint described above: it is more informative in that it directly refers to the discourse topic: refugees.

ST6 UNHCR (United Nations High Commissioner for Refugees) WHAT'S WRONG HERE?

Look at these nice happy people. Notice that each one has something: a tool or implement here, a bicycle or a briefcase there. All completely normal and unremarkable.

But wait. Something's amiss. That nice fellow near the bottom - third row down, second from the right. He doesn't seem to have anything.

Indeed. You see, he's a refugee. And as you can see, refugees are just like you and me except for one thing: everything they once had has been destroyed or taken away, probably at gunpoint. Home, family, possessions, all gone... (Newsweek, December 12, 1994, emphasis added)

What would you say about him, fourth row, second from the left, with the moustache? It's definitely him.

Though probably not. The unshaved guy with the dirty vest you are looking at, may be one of your neighbours.

The refugee could easily be the clean, decent person on the right. You see, refugees are people like us.

They differ only in one thing. Whatever they once had, has stayed behind. Home, family, possessions. All gone. They've got nothing any more... 


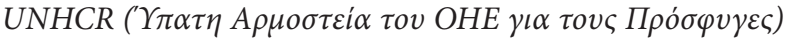
ПОIO $\Sigma$ EINAI O ПРО ФФҮГА

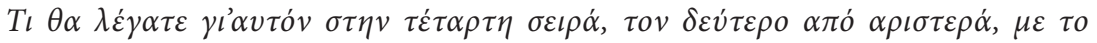

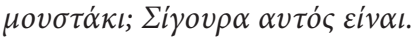

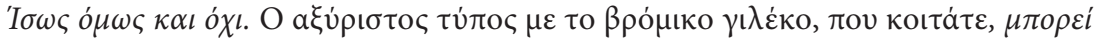

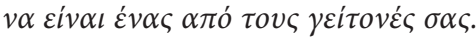

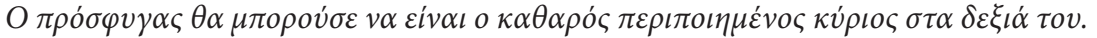

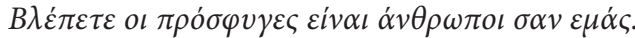

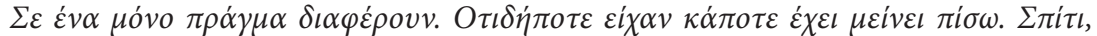

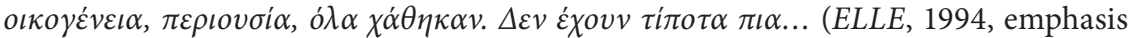
added).

Ad headlines are shown here to conform to press news headline constraints operating across English - Greek. This tendency reveals the affinity ads have to the press news genre and reflects aspects of selective identities of cultural audiences. Sticky captions, intended to appeal to local readerships, 'mirror' the linguistic character of their respective audiences and may allow safe conclusions about discursive preference across cultures.

The following section examines variation in ad translation strategies across commodity types, relative to reader profile. Ads are forms of discourses which make a powerful contribution to how we construct identities (Goddard 1998). Ad translation is, thus, shown to mirror fine aspects of audience identities and social practices across cultural settings.

\section{Across Commodity Types}

As mentioned above, soft-sell approaches to advertising (e.g. perfumes, cosmetics, beers, liquor) differ from hard-sell ones (e.g. office-equipment). In soft-sell approaches impression is more important than information, whereas in hard-sell approaches consumers are assumed to be more information sensitive (Rotzoll 1985). The question arises as to how these varying approaches to advertising in English may influence translator behaviour. Do these specific linguistic patterns make captions sticky in a TT, and if so, what aspects of target audiences' collective identities do these patterns reveal?

\subsection{Business-oriented Ads}

A fairly strong linguistic preference in business-oriented ad translation is nominalizing. Nominalizations are negative politeness devices (Brown and Levinson 1978/1987) which raise tenor. Even if it turned out that English is a more 'verbal' (rather than 'nominalizing') language than Greek, in which case nominalizations would not have the same formalization effect in Greek, the strong preference for nominalization in business-oriented ads (as opposed to cosmetics ads) does have a tenor-raising effect in the Greek TT. Besides, Greek has a gerund-type construction, which would have done the job better, had there been a preference for lower-tenor constructions, in this context.

Greek TT business-oriented ads seem to strongly favour nominalizations, relative

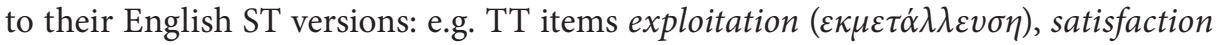




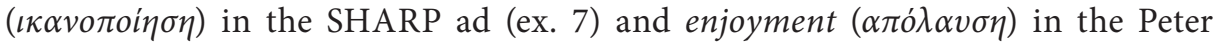
Stuyvesant ad (ex. 8) are employed to render ST verbal constructions.

ST7 SHARP - SF-7850 The Compact Copier Loaded with Big Copier Functions BECAUSE SMALL SIZE SHOULDN'T MEAN SMALL PERFORMANCE

The Sharp SF-7850 packs enough features in its desktop design to satisfy most office needs. A wide zoom range from $50 \%$ to $200 \%$ is just the start in a long list of special features that make the SF-7850 the copier choice for your office...(Brochure, 1995)

TT7 SHARP - SF-7850 The Ideal Copier for exploitation of space and time BECAUSE SMALL SIZE DOESN'T MEAN SMALL PERFORMANCE

The Sharp SF-7850 has gathered big features in small size and category, for the satisfaction of office needs, even in small space.

The ZOOM feature from $50 \%$ to $200 \%$ is just the start in a long list of special features that make it the copier of your choice...

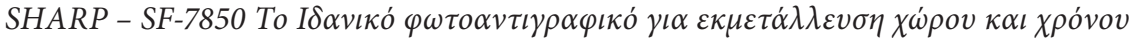

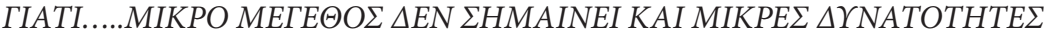

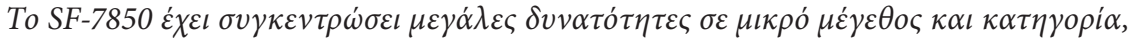

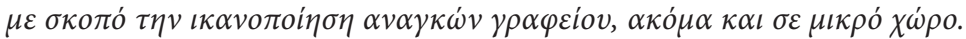

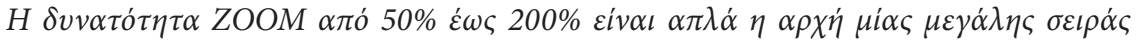

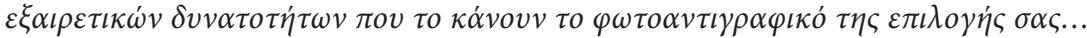

(Prospectus, 1995)

ST8 PETER STUYVESANT - FILTER

Rich choice tobaccos plus the Miracle Filter make Peter Stuyvesant The International Passport to Smoking Pleasure ...so much more to enjoy!

TT8 Rich choice tobaccos plus the Miracle Filter make Peter Stuyvesant The International Passport to Smoking Pleasure ...for even more enjoyment!

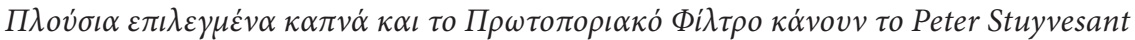

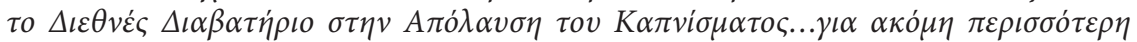
$\alpha \pi \delta ́ \lambda \alpha v \sigma \eta !$

Another preference which also raises formality is passivizing active verbal constructions in Greek TTs, in a language (Greek) which generally favours active constructions. For instance, Greek TT are required, is reduced, is minimized render English ST active constructions, requires, reduce, minimize in ex. 9.

ST9 SHARP - SF-7320

A USER-FRIENDLY, DEPENDABLE COPIER WITH AN EMPHASIS ON FUNCTIONALITY

Assured copy quality and easy-to-operate control panel make the SF-7320 unique among compact copiers. The SF-7320 produces 13 copies per minute and requires only 35 seconds for warm-up....

Short warm-up time. The SF-7320 features a surprising quick warm-up time of approx. 35 seconds.

Stand-by mode. To minimize noise and reduce energy consumption during the standby mode, the fan motor stops automatically when the SF-7320 is not in use....

TT9 SHARP - SF-7320 THE SMALL, USER-FRIENDLY, DEPENDABLE COPIER Assurance of copy qualities and easiness in operation make SF-7320 unique. It produces 13 copies per minute and only 35 seconds are required in order for it to warm-up.... 
Short warm-up time. The time that is required for warm-up and operation is very quick, just 35 seconds.

Stand-by mode. During stand by, noise is minimized and at the same time energy consumption is reduced. ...(Brochure, 1995)

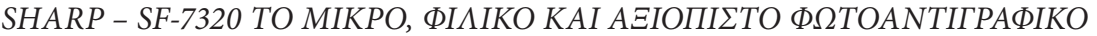

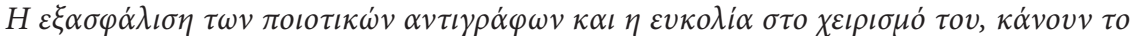

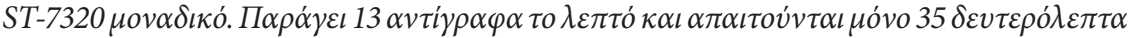

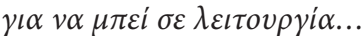

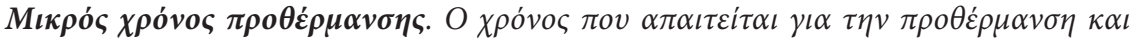

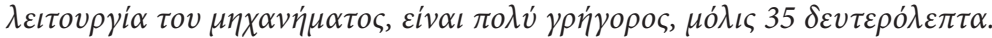

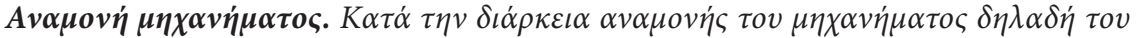

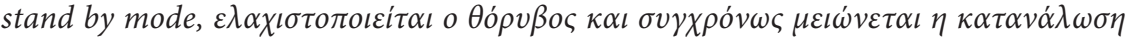

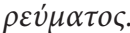

(Prospectus, 1995)

These distance-creating devices (nominalizations and passive constructions) are backed by other shifts that have a similar tenor-raising effect. In ex. 10, the name of the stockbroker is omitted, in favour of his professional post/social position. This has a distancing effect on target readers because the impression of interpersonal proximity is erased.

ST10 IBM, 0S/2 WARP - JULIAN YOUNG JUST GOT WARPED

In a typical day, stockbroker Julian Young makes his personal computer do some very unusual things... (PC Magazine, February 1995)

TT10 IBM, 0S/2 WARP - THIS STOCKBROKER JUST GOT WARPED

During a typical day, the stockbroker in the picture makes his personal computer do some very unusual things...

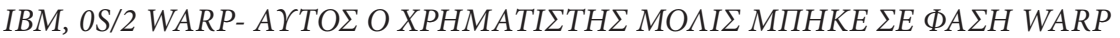

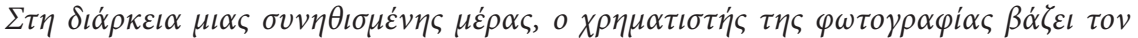

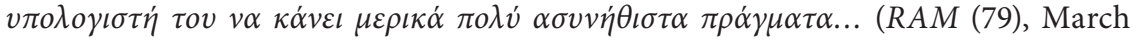
1995)

Reverse tendencies, e.g. tenor-lowering devices, do appear in business-oriented ad types but they are not frequent. Distance-reducing approaches to ad translating should be assumed to address audiences that are not necessarily professional and purely business-oriented. The following SIEMENS ad is an instance of this: it advertises resource conservation through gas turbines, high voltage transmission and solar panels, as efficient, safe, clean and economical energy resources. The target version is addressing a wider audience rather than businessmen alone and comprises distancereducing devices.

\section{ST11 SIEMENS - FOR THE POWER OF A NEW GENERATION}

Simply meeting today's demand for energy is not enough. The challenge is to go beyond. To increase efficiency. To conserve resources. And to offer cost effective, renewable energy solutions. At Siemens, we're going beyond...

Siemens power engineering saves resources for tomorrow. (Newsweek, Nov. 22, 1993) 


\section{TT11 SIEMENS - WHO'S GOING TO WARM THEM AFTER 40 YEARS?}

Being able to face everyday needs in energy is not enough. The challenge is to proceed further. To increase efficiency. To conserve resources. To offer economical and renewable energy sources. In Siemens, we do exactly this...

And in our country, since the beginning of the century, with 1.800 Greek employees and 3 factories today...

\section{Siemens. Close to human needs.}

\section{SIEMENS - ПOIO $\mathrm{\Theta A}$ TOY $\Sigma$ ZE}

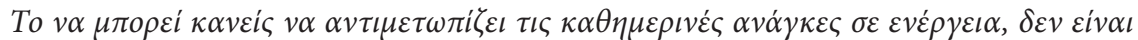

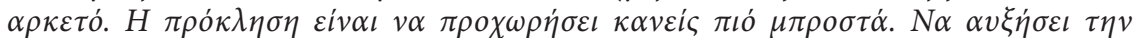

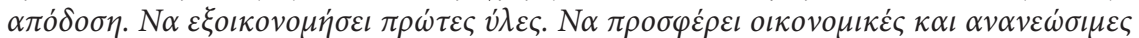

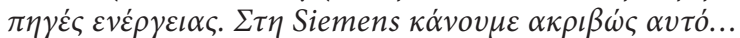

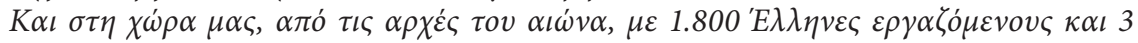

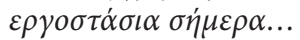

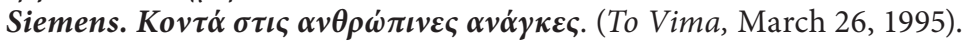

In the headlines, the target version creates positive associations by making reference to warmth (which connotes security) and to human subjects (Who's going to warm them..?). The presence of humans is also ensured through a visual which accompanies the Greek version: a picture of young people with their hands raised in a gesture of clapping, as if engaged in some public spectacle. That humans and human needs are the focus of the company, against a background of an impersonal and inhuman way of life, is also evident in the closing sentence, which makes reference to human needs. The TT further enforces group membership (see insertion of TT in our country..., which lowers tenor and reduces interpersonal distance). Nominalization, a distance creating device, which was opted for in the previous advertisements, is avoided here:

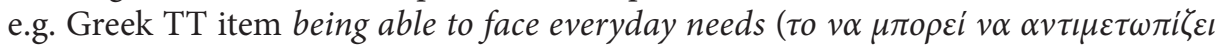
$\tau \iota \varsigma \kappa \alpha \theta \eta \mu \varepsilon \rho \iota v \varepsilon \varsigma \alpha v \alpha \dot{\alpha} \kappa \varepsilon \varsigma)$ is a verbal construction in Greek which could have been rendered in terms of a pure nominalization ( $\eta \delta v v \alpha \tau o ́ \tau \eta \tau \alpha \alpha v \tau \iota \mu \varepsilon \tau \omega \dot{\omega} \tau \iota \sigma \eta \varsigma \tau \omega v$ $\kappa \alpha \theta \eta \mu \varepsilon \rho v \omega \dot{v} \alpha v \alpha \gamma \kappa \omega \dot{\omega}$ ). The nominalization is avoided, however, as it would create unintended formality and interpersonal distance.

In business-oriented ad translation, rendition of linguistic features is adjusted relative to the image of addressee the producer intends to promote. The more business-oriented the commodity, the stronger the tendency for raising tenor level in the Greek TT through tenor-raising devices, regardless of whether the feature is opted for the English ST. The SHARP photocopiers (exs. 9 and 10) trigger more nominalization and passivization devices in the Greek TT, than the tobacco ad (ex. 8) does. By contrast, in the Siemens ad (ex. 11), which is more family-oriented or simply addresses a wider audience, nominalizations tend to be avoided and interpersonal aspects of meaning are promoted either through the text or through the visual. Despite the TT distance-reducing devices, however, the Siemens translator IS interested in maintaining distance between addresser-addressee. This is manifested e.g. in the use of the Greek TT indefinite pronoun one ( $\alpha \alpha v \varepsilon i \varsigma, 1.1)$, which adjusts definiteness to generically appropriate levels.

No matter the linguistic feature opted for in the English ST, the preference in Greek fluctuates relative to the reader profile the translator-advertiser intends to address. In the photocopier ads, the distance-creating devices are enforced and tenor level raised. In the Siemens ad, distance is decreased between text and readership and tenor lowered. 
Fluctuation in the preferred TT patterns of linguistic expression is observed in cosmetics, as well, but in that context, the specifics of interpersonal communication between advertiser and consumer trigger variation for a different reason.

\subsection{Cosmetics Ads}

A lot has been said about how gender may be affecting discourse construction or what implications are generated through language use in particular environments. Notions in advertising may be employed in ways other than the ones observed in dictionaries, bearing consequences for the significance of language as a tool for imposing ideologies or language as a reflection of socially preferred traits and practices. In Japanese advertising addressed to female consumers, the very notion of intelligence "describes appearance rather than mental capacity, and thus seems closer in its meaning to words such as 'elegance,' 'femininity,' or 'sophistication,' than to words like 'brightness' and 'cleverness'..." (Tanaka 1994: 111). Likewise, 'individualism' in Japanese turned out to be a search for high fashion and social approval rather than having one's own style. Myers (1994) points to the interrelation between gender and advertising: he claims that the strategies employed for defining ourselves as in some way different are strongly tied to gender and that few ads work the same for men and women.

Options in advertisements are assumed to create a feeling of solidarity with the advertiser, and hence, a positive response on the part of consumers towards the product, regardless of whether consumers believe the messages to be true. This is how 'covert' communication works in advertising, i.e. by making a set of assumptions manifest to the hearer "without making this intention mutually manifest" (Myers 1994: 41).

The present section shows how interpersonal distance between advertiser and consumer may be manipulated in Greek target versions of cosmetics ads to cater for stereotypical images associated with the gender of potential consumers in a Greek (target) society. There seem to be two competing forces which affect translator behaviour in cosmetics ads.

On the one hand, there is an interpersonal attitude developed in terms of

- TT first and second person reference (e.g. Greek TT we present you FRUITION, in TT12),

- direct forms of address (e.g. there is a direct exhortation realized through an imperative, in Greek TT of Y\&Z Cosmetics: Stop time now! to render an evaluative ST statement: A Sensitive Cream for a Sensitive Area, in ex. 13), or

- verbal rather than nominalized constructions (e.g. ST improvement $\rightarrow$ TT is improved, in Estée Lauder-FRUITION, ex. 12).

Nominalizations are not a 'must' any more: they may either be avoided or opted for. Besides, in ex.12, an opening sentence is added in the TT, which favours a suspensecreating attitude: Find out about..., at the beginning of Greek TT, enforces a storytelling attitude which favours an interpersonal, rather than transactional, aspect in interaction.

ST12 ESTÉE LAUDER - Underneath the skin you see is the skin you want. Now Estée Lauder brings it to FRUITION- Triple ReActivating Complex... 


\section{Our research shows:}

- Up to $60 \%$ increase in skin clarity. Within two weeks.

- Up to $40 \%$ improvement in skin texture and tone... (She, Feb. 1995)

TT12 Find out about the secret that more than a million women already know about. ESTÉE LAUDER - Underneath the skin you see is the skin you want. We present you FRUITION-Triple ReActivating Complex ...

Our research section has proven that:

- By $60 \%$ skin regains it's lost clarity within two weeks.

- By $40 \%$ skin's tone and texture is improved...

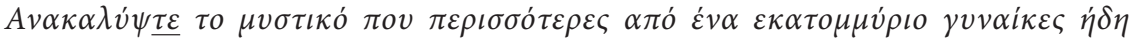

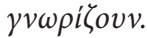

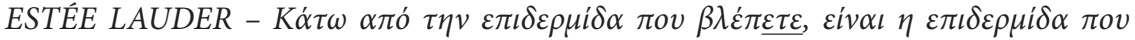
$\theta \dot{\varepsilon} \lambda \varepsilon \tau \varepsilon$.

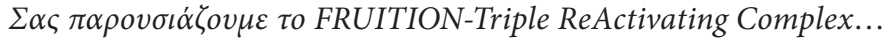

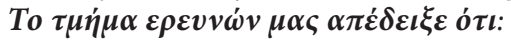

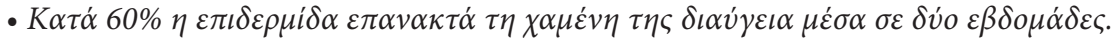

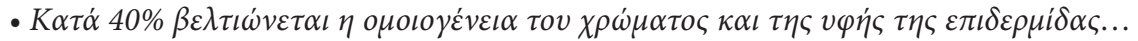
(Marie Claire, March 1995)

ST13 Y \& Z COSMETICS: Anti Wrinkle Eye Cream. - NEODERMA

A Sensitive Cream for a Sensitive Area. It may seem hard to believe...

TT13 Y \& Z COSMETICS: Anti Wrinkle Eye Cream. - NEODERMA

Stop Time Now...! It may seem impossible...

$Y$ \& Z COSMETICS: Anti Wrinkle Eye Cream. - NEODERMA

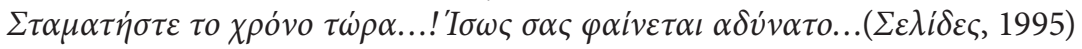

On the other hand, there are shifts which increase interpersonal distance. An obvious one is the use of TT second person plural pronouns in ex.12. Greek has a tu/vous distinction in its verbal system. Singular second person pronouns would have been too direct. The choice of pronouns, Myers claims, "carries significance in a wide range of texts that represent some sort of interaction" (1994: 87).

The assumption is that distance-reducing devices in cosmetics ads, which are intended to make the text appealing to female readerships, somehow jeopardize the persuasive power of ad discourses by creating too close a relationship between text producer and audience. Thus, translators may be assumed to boost the persuasive force of arguments by allowing addressees more mental space and responsibilities in processing the message. This may be manifested in terms of omitting logical connectives to leave the responsibility of retrieving logical relations to addressees, as in TT14: two connectives, while and and, are ignored in the Greek TT, which is rather infrequent in English-Greek translation practice. Likewise, translators may also be elaborating on the reliability of the source the information comes from.

Translators, thus, may eliminate logical markers and leave addressees to infer relations between parts of discourse, as in ex. 14,

ST14 MAX FACTOR - Get Even...

New Balancing Act balances combination skin. Oil absorbing powders subtract shine, while oil free hydrators add moisture. And that equals a finish that stays balanced, stays even.

(Marie Claire, October 1994). 
TT14 MAX FACTOR - A Balancing Relation...

New make up Balancing Act. It balances combination skin. It makes shine disappear through absorbing powders. [] It adds moisture through hydrators. [] It creates balance... A perfect make-up finish...Yours.

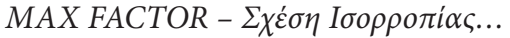

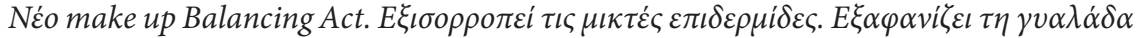

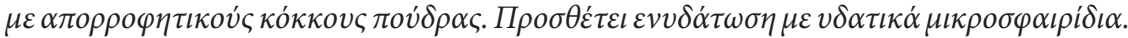

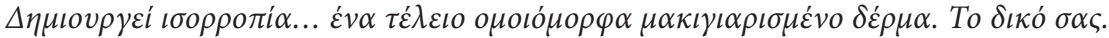
(Elle, December 1994)

or (b) elaborate on the scientific research these products have been a result of, as shown in ex.15. In the Helena Rubinstein-Intercell TT (ex. 15), reference is made to the brand laboratories to enforce product reliability.

ST15 HELENA RUBINSTEIN- INTERCELL Anti-Time Principle ...And is based on a fundamental discovery that cells continually communicate with each other - a process known as intercellular communication... (Cosmopolitan, November 1991)

TT15 HELENA RUBINSTEIN- INTERCELL Anti-Time Principle

It is based on a fundamental discovery: intercellular communication. Now, Helena Rubinstein laboratories prove its crucial role in skin's youth...

HELENA RUBINSTEIN- INTERCELL Anti-Time Principle

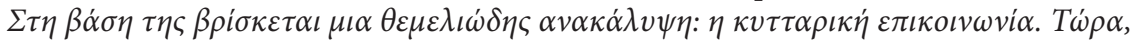

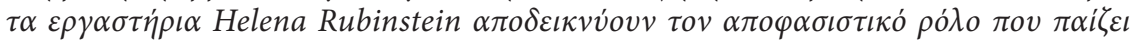

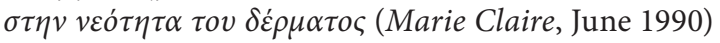

In the R-Vincaline ad (ex. 16), reference is made to a biotechnology method used in the preparation, to the same effect. Likewise, in ex. 12, English ST item research has been turned into Greek TT research section ( $\tau \mu \dot{\eta} \mu \alpha \underline{\varepsilon \rho \varepsilon v v \omega ́ v}$ ), which enforces the presupposition that there is considerable research activity going on behind the scenes.

\section{ST16 HELENA RUBINSTEIN, R-VINCALINE}

...Vincaline is a unique natural active ingredient extracted from the seed of the Madagascan Periwinkle, which has a powerful effect on cellular renewal.

TT16 HELENA RUBINSTEIN, R-VINCALINE

...Vincaline is a natural active ingredient with a unique potential in cellular rejuvenation, a natural extract, through the biotechnology method, from the seeds of the Madagascan plant pervinca.

\section{HELENA RUBINSTEIN, R-VINCALINE}

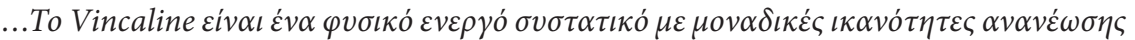

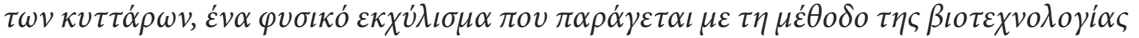

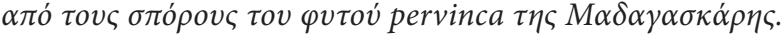

Ex.1 provides another instance of this: ST Essence of Beauty is rendered in terms of TT item Knowledge of Beauty (

In ad translating, translator behaviour seems to be fluctuating relative to the gender identity of intended addressee. Male-dominated business environments tend to trigger a transactional attitude on the part of translators, in terms of favouring nominalization, passivization and other devices that raise tenor level. Cosmetics, in 
this data set, which mainly address women are assumed to require a more interpersonal attitude in interaction.

Fig. 1 summarizes tendencies in Greek TT ad versions with respect to the use of preferred linguistic devices relative to commodity type.

FIGURE 1

Tenor Modification in Greek Versions of Ad Types.

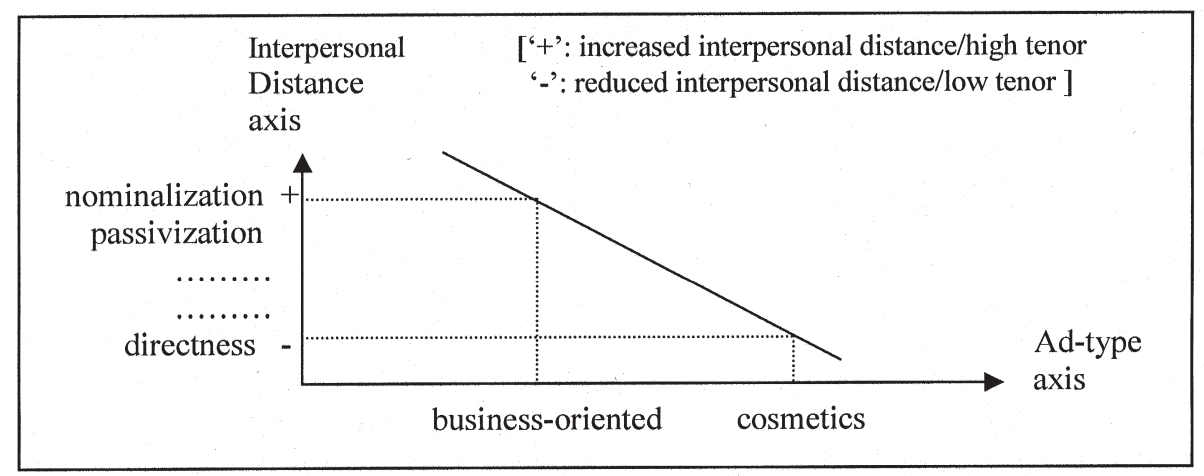

Both tendencies ARE occasionally balanced in terms of certain devices for the sake of persuasiveness: distance-reducing ones may appear in business-oriented ad types and distance-creating ones in cosmetics ads. However, cosmetics ads seem to register a most unpredictable translator behaviour relative to business-oriented ad types. The assumption has been that lowering tenor in cosmetics ads threatens the mental space consumers would need for the persuasion strategy to be effective and, thus, unexpected devices in the English-Greek translation practice are opted for in cosmetics TTs. In fact, the 'unexpected' instances of translator behaviour in cosmetics advertising are numerous and diverse. Directness has been shown to be avoided in EnglishGreek cosmetics ad translation: this has been realized e.g. in terms of avoiding the imperative in exhortations (directness) and silencing first and second person pronouns in addressing female consumers (Sidiropoulou 1998a).

\section{Identities in Advertising}

As mentioned above, ad discourses are unique in carrying imprints of linguistic identities. Ad translation is likewise expected to register culture-specific versions of identities. This is because effective advertising should sound like everyday conversation, although this everyday life depicted in advertisements is a rather specialized academic term. As Myers (1994) argues,

it is quite a trick to get the conversational sound [in ads] while also getting in all the product information demanded by a client... To understand the importance of everyday life in ads, and the difficulty of evoking it, we need to think of 'everyday life' with quotation marks around it, as a specialised academic term like 'Romanticism' or 'proletariat'... (1994: 105, emphasis added). 
This study has attempted to reveal aspects of the language tricks used in evoking everyday life in advertising across languages. In English-Greek ad translating, 'evoking everyday life' involved manipulating persuasive devices and tenor level in TT or features like the amount of information to be offered in particular situations. Figure 2 summarizes the types of shifts referred to in this study, relative to the context these shifts are associated with.

FIGURE 2

Types of Shifts Referred to in this Study.

\begin{tabular}{|l|l|l|l|l|}
\hline $\begin{array}{l}\text { Feature } \\
\text { manipulated }\end{array}$ & $\begin{array}{l}\text { logical relations } \\
\text { in ad persuasion }\end{array}$ & $\begin{array}{l}\text { amount of info } \\
\text { in ad headlines }\end{array}$ & $\begin{array}{l}\text { Nominalizing, } \\
\text { passivizing }\end{array}$ & $\begin{array}{l}\text { Interpersonal } \\
\text { proximity and } \\
\text { balancing devices }\end{array}$ \\
\hline Specific to & Culture & Genre & Commodity type & Gender of addressee \\
\hline
\end{tabular}

Shifting logical operators is assumed to relate to a culture-specific trait for it is widely encountered in the English-Greek paradigm. The amount of info in ad headlines has been considered to vary relative to the generic conventions prevalent in press messages in general. Shifts in nominalizing and passivizing regulating tenor have been shown to vary with commodity type (business-oriented or cosmetics ads). Interpersonal proximity devices were ultimately associated with the gender of intended addressees.

Greek translators tend to raise tenor in business-oriented ads and occasionally contribute some lower tenor devices to adjust formality. In cosmetics ad translation, the tendency is reversed: tenor level is lowered in the Greek TT, while certain unexpected (in the Greek context) shifts are employed to increase interpersonal distance, evidently with a view to boosting the persuasive force of texts.

Fluctuation in tenor is assumed here to be targeted at individuals' personal needs: self-respect, security, warm relationships with others, sense of belonging, fun/enjoyment etc. Self-respect and security have been shown to be top priority personal needs (Kahle 1984, reported in Fowles 1996) according to a national survey which examined the values of Americans and implications for consumer adoption. Raising tenor caters for self-respect; lowering tenor facilitates warm relationships with others and possibly the sense of belonging. Ad translation, hence, mirrors society in that it shows that male consumers are associated with top priority needs, while female consumers are more readily associated with secondary needs on the list.

Feminist scholars would consider this attribution of personal needs to gendered social groups a manifestation of the patriarchal effort at the subordination of women. Numerous inequalities have been pointed at, with respect to gender, in the advertising literature. For instance, production has often been considered men's work in the advertising business, while consumption women's. Women are usually claimed to be gazed at by males in advertising and not vice versa (Myers 1994). Reflection of gendered identities is manifested in the depiction of almost every social group. Gendered depiction of sexes begins early in advertising (Umiker-Sebeok 1986, in Fowles 1996: 204-205): depictions of children in American print advertising have shown that females are displayed, in ads, in a vulnerable state (e.g. alone, asleep) or as an organic part of the domestic setting, whereas boys are presented in an outside setting. 
Likewise, male adolescents appear aggressive and in control, while female adolescents 'experience a kind of second infancy' in magazine ads.

An instance of gender-bias, in the present advertising data, may be the fact that sexual connotations are humourously allowed in business-oriented ads (ex. 7, Because small size doesn't mean small performance) rather than in cosmetics ads. Moreover, the suggestion that production is primarily men's business, while consumption women's seems to be verified in the context of this study. Thirty university students in the Faculty of English, National and Kapodistrian University of Athens, all native speakers of Greek, were given a set of six TT ad versions (three business-oriented ads and three cosmetics ads) and were asked to consult their insight into mother tongue and native cultural presuppositions in order to suggest the gender of the advertiser. In the business-oriented ads, the advertiser was assumed to be male by $90 \%$; in the cosmetics ads, the advertiser was assumed to be female by 76\%. Cook (1992) addresses the issue 'who the speaker is' in advertising. Like in literary fiction, he claims, in which authorial, narrative and characters' voices merge, the 'I' and 'we' who speak the 'you' of the text is unclear. 'We' is usually the manufacturer, 'I' the adviser, 'he'/ 'she' the person who does not use the product, distanced by the pronoun, while 'you' is the most divergent form of address.

Attribution of needs, in this data set, is hence sex-biased, as it is in society, in that it considers top priority a different set of personal needs for men (in businessoriented ads) and women (in cosmetics ads).

The question arises in advertising research as to whether ads create social values or simply mirror the ones that already exist in a society. Ad translating has the potential to both reflect already existing values and to import new ones in target environments more than any other genre. Foreign gender (or other) stereotypes are expected to reshuffle local cultural values and needs leaving clear imprints on local discourses. As Fowles (1996: 199) claims, sex may be biologically given, but masculinity or femininity of gender is "culturally determined" and, thus, the inflow of discursively realized gender stereotypes, in ad translation, is always worth studying for its potential to reflect and mould social values. Advertising "forms a vast superstructure with an apparently autonomous existence and an immense influence" (Williamson 1978: 11). That is why advertising companies invest so much in acquiring mechanisms that can manipulate the power of connotations in language, for the company's own benefit.

An open research problem is what form this moulding-the-social-values potential can take, how the practices of remoulding can be manifested in translated advertising discourse. They probably take the form of competing tendencies which coexist in the same genre or text. For instance, if ads show affinity to the news genre and if taboo and offensive items tend to be erased in news reporting translation into Greek (Sidiropoulou 1998b), how can the sexual connotations be transferred intact in the SHARP-7850 ad, ex. 7? It may be the case that Greek advertising allows this playful attitude with language which Greek news reporting conventions occasionally resist. Instances of humour are modified and downgraded in Greek TT versions of ads (Sidiropoulou 1998a), but this may be due to their culture specificity. Deliberate ambiguity IS a typical device for creating puns and humourous captions in original ad versions on Greek TV. An interesting attempt would be for researchers to measure 
the ratio of interpersonal/transactional information per ad type in ST versions of ads in order to identify modifications in that ratio across cultures.

Advertisements, Fowles claims, "take on the status of fascinating cultural documents" in pursuing the "mission to make manifest the most deeply felt needs of the broadest number of people" (1996: 167). In the same vein, ad translating provides culture-specific versions of these cultural documents, which are invaluable in that they reflect cultural variation in the manifestations of these deeply felt needs.

\section{NOTES}

1. I am indebted to Mr. D. Alexopoulos, director of LESPOT Productions, McCANN-ERICKSON WORLDGROUP HELLAS, for providing me with the audio-visual material, in August 2003.

2. Strategy 1 applies to commodities in which "the brand name is very strong and the product needs very little verbal support." This no-change strategy may be observed in perfumes, cigarettes, alcohol, soft drinks, CDs etc. The main target of this global type of advertising are businessmen and young people. Strategy 2 plays on "positive stereotypes of the originating culture," retaining logo, slogan etc. Such an approach is used for many of the above products. The cultural origin of the product is felt to be an asset and is thus stressed in the advertising. Strategy 3 is the least frequent because it does not cater for 'cultural demands' in the new market (e.g. tourist materials, label brochures etc.) Category 4 "makes tactical adjustments in terms of addressee needs and expectations, cultural norms, frames of reference" and is the dominant strategy in international advertising. Category 5 builds on an existing original but allows modifications which cannot deviate substantially from the original concept. In this case, cultural versions are angled to stress "different marketing objectives in the different countries, while the visual might well be a picture of a bottle in all three cases." In category 6 , independent local advertising campaigns may "produce different advertisements with different visuals and texts for each country" (Smith and Klein-Braley 1995:182-183).

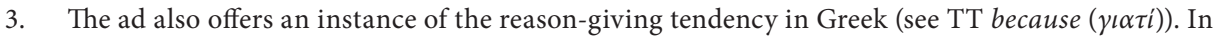
addition, the closing sentence enforces interpersonal aspects of interaction: e.g. TT direct questioning and evaluation (isn't it surprising...?). See also the concluding utterance in the TT headline version: Greek TT So, don't you worry! comprises a result connective, which is an instance of the enforcing-the-discourse-connection tendency observed elsewhere.

\section{REFERENCES}

Adab, B. and C. Valdes (eds) (2004): "Introduction," in Key Debates in the Translation of Advertising Material, The Translator 10-2, pp. 161-177.

Brown, P. and S. Levinson (1978/1987): Politeness - Some Universals in Language Usage, Cambridge, CUP.

Coок, G. (1992): The Discourse of Advertising, London, Routledge.

Fowles, J. (1996): Advertising and Popular Culture, London, Sage.

GodDARD, A. (1998): The Language of Advertising, London, Routledge.

Myers, G. (1994): Words in Ads, London, Arnold.

Rotzoll, K. (1985): "Advertisements," in van Dijk, T. (ed.) Discourse and Communication, Berlin, Walter de Gruyter.

SÉGuinot, C. (1994): “Translation and Advertising: Going Global,” Current Issues in Language and Society 1-3, pp. 249-265.

Sidiropoulou, M. (1995): "Headlining in Translation: English vs. Greek Press," Target 7-2, pp. 285-304.

Sidiropoulou, M. (1998a): “Advertising in Translation: English vs. Greek,” Meta 43-2, pp. 191204.

Sidiropoulou, M. (1998b): "Offensive Language in English-Greek Translation," Perspectives 6-2, pp. 183-199. 
Sidiropoulou, M. (2004): Linguistic Identities through Translation, Amsterdam/New York, Rodopi.

Smith, V. and Ch. Klein-Braley (1995): "Advertising - A five-stage strategy for Translation," in Snell-Hornby, M., Jettarová, Z. and K. Kaindl (eds) Translation as Intercultural Communication, Amsterdam, John Benjamins.

TANAKA, K. (1994): Advertising Language, London, Routledge.

Williamson, J. (1978): Decoding Advertisements, London, Marion Boyars. 